\section{POWER, PESTULANCE, WEATHER, AND WAR}

This month's focus includes a strong emphasis on the lifecycle approach to epidemiology. Diana Kuh and her colleagues provide us with an apposite Glossary in the Continuing Professional Education section, which demonstrates how this approach has come of age over the past few years; and we also carry several other contributions that draw upon it. The Gallery includes a photographic version in terms of comparison of classroom photographs of school children in London at 25 year intervals, and other papers include:

- a study of socioeconomic status over the life course and stages of cigarette use;

- the influence of social class in childhood, young adulthood, and middle age;

- an investigation of the risk factors for symptomatic osteoarthritis in women.

See pages $758,778,802,816,823$

As the Glossary brings out, the life cycle or life course approach can provide powerful angles on the accumulation of risk, birth cohort effects, chains of risk, critical periods, induction and latency periods, resilience, susceptibility, trajectory, transition and turning points among other things. All of these seem relevant in one way or another to the continuing sagas of SARS, the war in Iraq, and the unfolding story of weather and warm and cold conditions. At the heart of each of these in turn lies the need for fit for purpose surveillance systems. Something else that is tackled this month.

As I write, North America has just experienced probably the largest ever power cut, and the French health chief,
Lucien Abenhaim, has resigned his post after 5000 heat related deaths in France-in part attributing the disaster to a lack of information and warning signals to enable the public health system to respond. An editorial in the British broadsheet, the Independent (Tuesday, 9 August 2003), however, points out that "France is not the only country to have experienced uncommon temperatures this year. The heat in Italy, Spain, and even here in Britain has broken all records. Before we condemn the French for lounging on the beach rather than tending to their heat stricken, we need to establish what happened elsewhere. Regrettably [.] we have not even started to find out." In their editorial, Ballester and colleagues put these issues in a public health context and identify a framework for further research and policy development. The Research section carries two relevant contributions: one from Healy on excess winter mortality in Europe, and one from Donaldson and Keatinge on the influence of social class in working and retired age groups on cold related mortality in England and Wales, and in Speaker's Corner, Choi and Ackland argue for the systematic development of public health surveillance, drawing comparison with the architectural structures of town planning.

\section{See pages 759, 784, 790, 783}

A substantial part of this issue is given over to SARS in one form or another. We include one contribution from Chau and Yip exploring the back projection method to estimate the infection curve of SARS in Hong Kong, and a methodological paper from Choi and Pak describing a simple approximate mathematical model to predict the number of outbreak cases and deaths. Nine views were sought from round the world on whether the SARS epidemic will recur. Not surprisingly, there is some disagreement about this, but the bottom line appears to be that vigilance and preparation are essential. In Hong Kong alone, the costs of this year's outbreak are estimated to total 8 to 10 billion Hong Kong dollars, in addition to almost 300 lives lost.

See pages $766,831,770$

In Iraq the aftermath of the war rumbles on, with huge public health challenges to be faced. Ridde describes some of the difficulties on the ground of meeting the humanitarian needs, and argues that the process of rehabilitation must be participatory and bottom up; a challenge addressed in relation to the more general issue of participation in health last year in a valedictory symposium for Professor Elizabeth Russell of the University of Aberdeen. We would welcome more contributions from the public health frontline.

\section{See pages 760,762}

Three final offerings:

- a contribution from North America on labour market income inequality and mortality;

- the occupational health risks of women brothel workers in Israel;

- and a fascinating editorial discussion of the role of shoe design in managing lower limb osteoarthritis.

See pages $792,809,763$ 